\title{
Detailed Analysis of Arch Foot of a Trough Girder and Arch Composite Bridge with FEA
}

\author{
Xun WU ${ }^{1, a,{ }^{*}}$, Zhong-Min TAO ${ }^{1, b}$, Jie LI ${ }^{1, c}$ \\ ${ }^{1}$ Dept. of Bridge Engineering, Tongji University, No. 1239, Siping Road, Shanghai, China

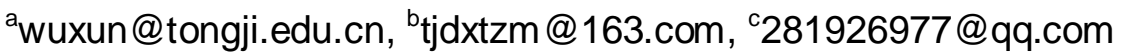 \\ ${ }^{*}$ Corresponding author
}

Keywords: Arch Foot, Finite Element, Stress Concentration.

\begin{abstract}
Tied-arch bridges have being widely used in railway for their beautiful shape and rigidity. Current analysis software Midas civil is applied in the overall analysis of many bridges, including the bridge in the article. However, there is huge amount of concrete in the arch foot of the arch bridge, which means that this part cannot be accurately calculated with the model of skeletal structures. Based on the principal of finite element method, Midas FEA plays an important role in the detailed analysis of complicated structure. As a result, it is applied in the local stress analysis of this arch foot.
\end{abstract}

\section{Introduction and Finite Element Division}

The tied-arch bridge has a span of $120 \mathrm{~m}$, whose girder is a trough girder. The height of the channel section at the middle of the span is $2.5 \mathrm{~m}$ and $3.0 \mathrm{~m}$ at the support. The arch rib has a shape of dumbbell whose height is $3.0 \mathrm{~m}$. Arch foot is a structure of large amount of concrete, in which buried the arch rib with other reinforced steel bar. Longitudinal and lateral pre-stressed tendons also lie in the arch foot, which makes it the most important and complicated part of an arch bridge and can only be analyzed with solid element. In respect of the model in FEA, part of the collar beam right before the first suspender are taken out along with the similar part of arch rib for detailed analysis. Concrete is simulated with solid element and steel plate of the arch rib is simulated with shell element while the lateral tendon is simulated with steel bar element. As longitudinal tendons are continuous in the bridge, they are not simulated in the model.

\section{Boundaries and Loads of the Model}

Cushion stones are set on the pier to serve as the support of the arch bridge. All the nodes of the cushion stones are restrained so as to simulate the simply supported structure. As the train on the bridge serves as mobile loads, these live loads are converted into dead forces along with deck pavement and simulated with uniformly distributed forces. As we can see in the Fig.1, there are some rigid arm elements in the visible sections. They do not exist in the bridge and are only used to exert forces to the local part of the whole bridge. As we know, there are axial forces, shear forces and moments on those severed sections on which the function of longitudinal tendons are also counted. All those rigid arm elements are connected with an important node, on which forces and moments are exerted. As a result, the detailed analysis of the arch foot is similar with the real situation.

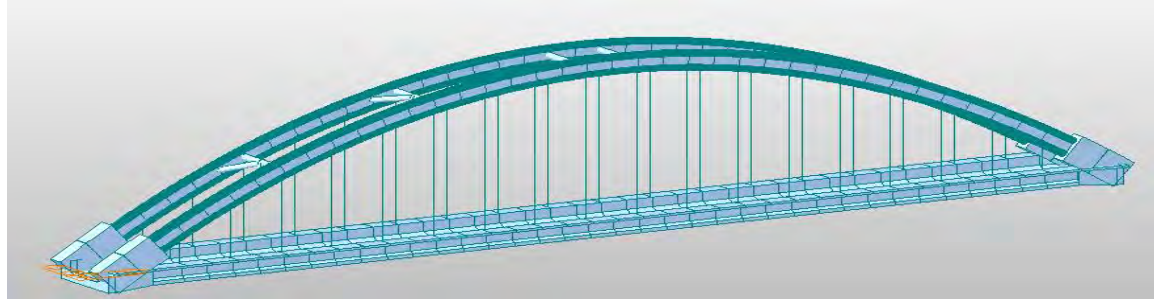

Fig. 1 Complete Finite Model of the Arch Bridge 

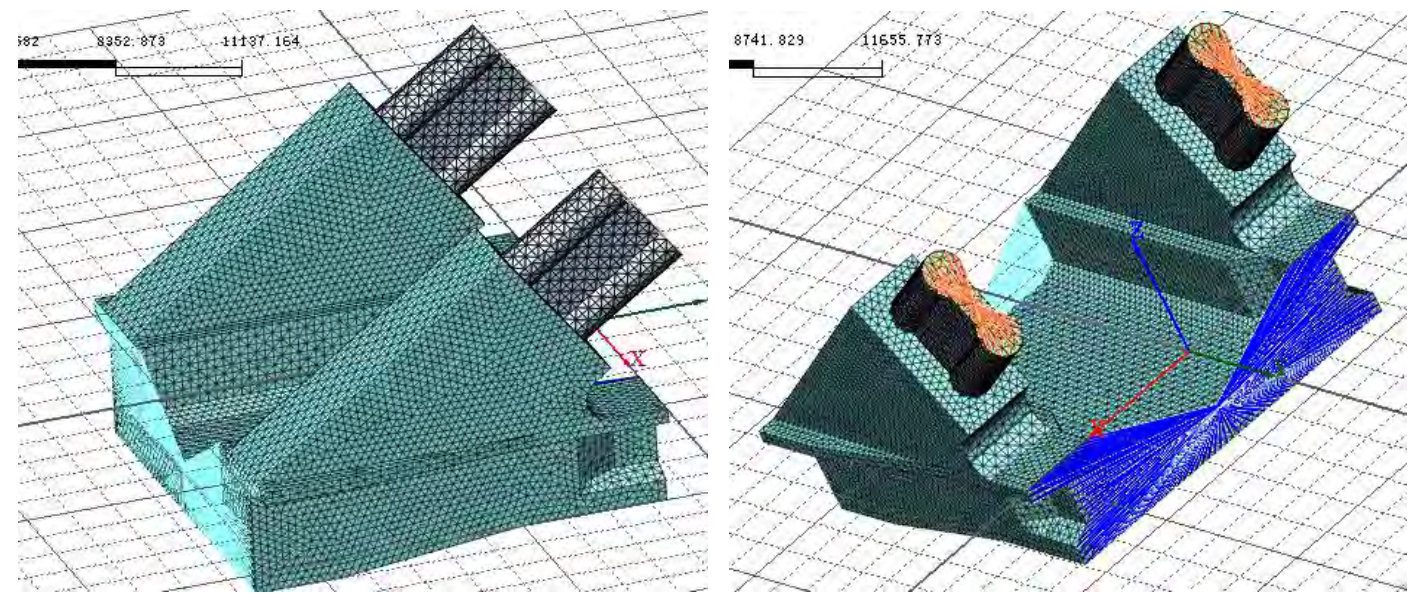

Fig. 2 Finite Element Model of Arch Foot


Fig. 3 Boundaries and Loads of Arch Foot

\section{Stress of Concrete}

The maximum longitudinal compressive stress of the concrete is mostly below 6.3MPa except some intersections of the deck beam and the arch rib, which reach as $10.6 \mathrm{MPa}$.However,concrete in the arch rib gets a stress of $15 \mathrm{MPa}$,especially on the part where the rib section changes. On the whole, longitudinal compressive stress of concrete complies with the code. In respect to tensile stress, there is some part that has high stress. However, it is due to the singular point of the model, which means that in the real bridge that will not happen. Lateral stress also complies with design code except the anchorage zone of lateral tendons. Measures will be discussed later.
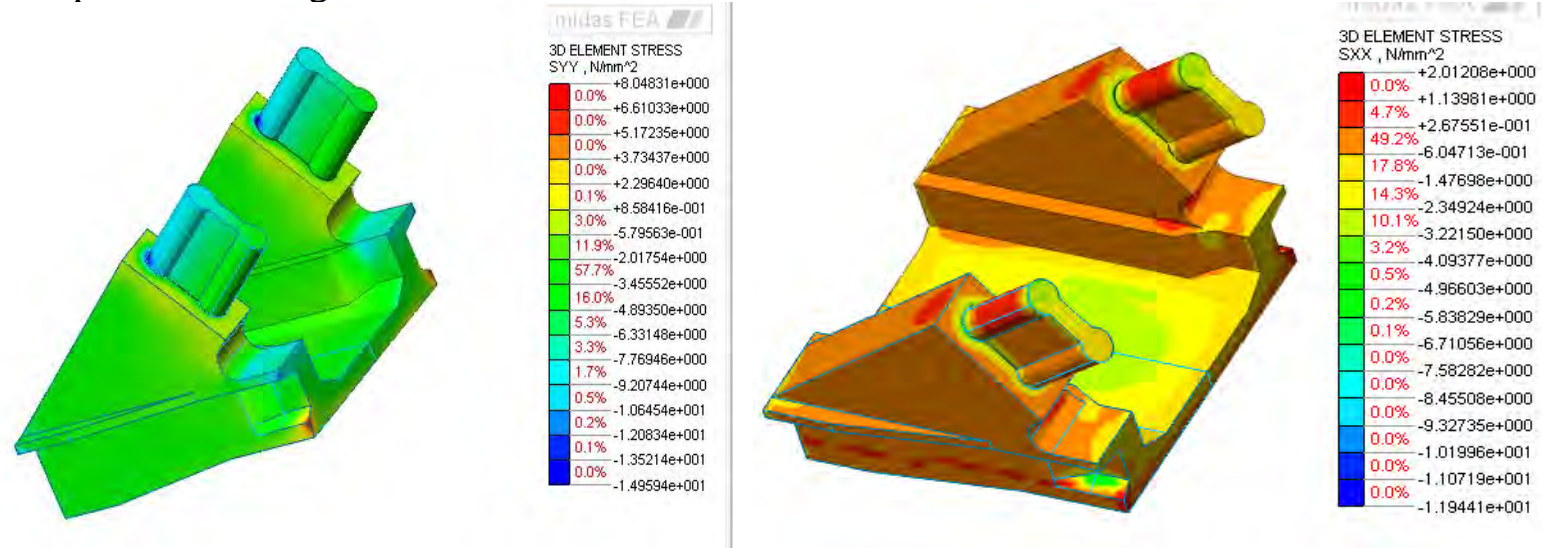

Fig. 4 Longitudinal and Lateral Stress of Concrete 
Principle tensile stress of concrete is mostly controlled below the allowed stress except some singular points. Special attention should be paid to part of concrete in the upper arch rib for in these parts, compressive stress is in danger of exceeding limitations. As a result, reinforced measures shall be taken, which is discussed later. Despite the fact that these parts are in danger, virtual locations that exceed the limited value of stress only lie in the cushion stones which can be replaced by steel cushion stones to solve the problem.
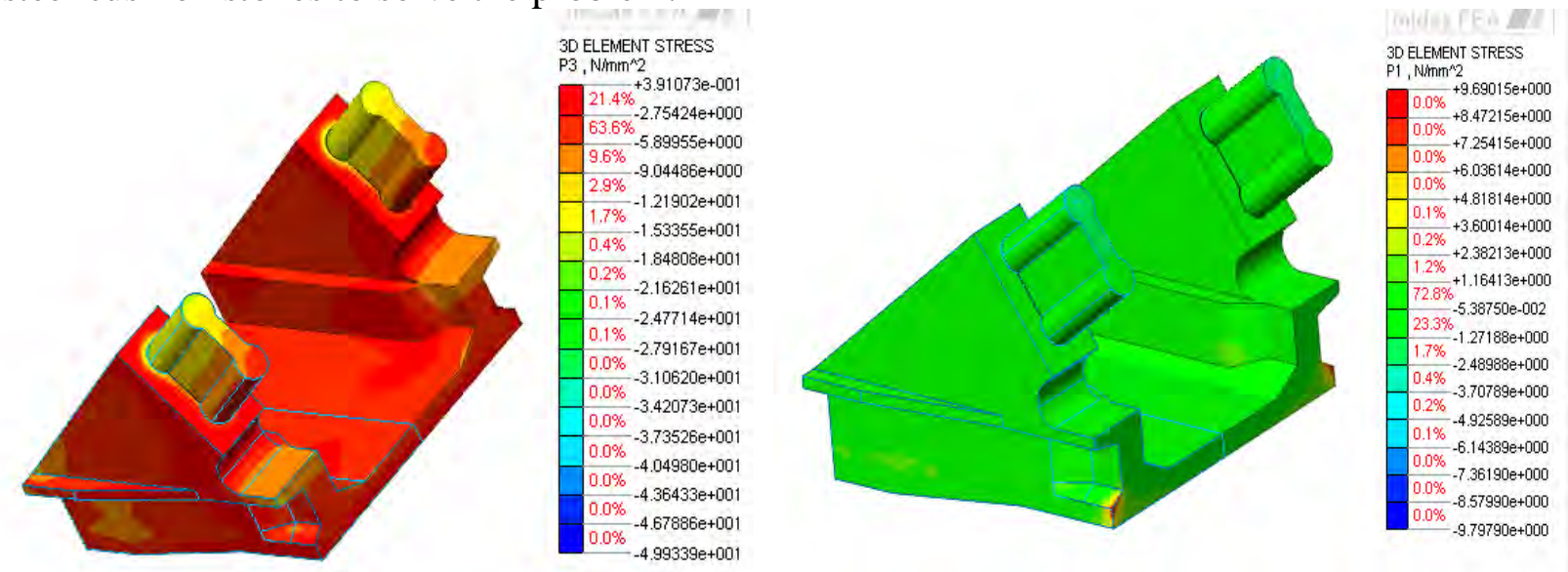

Fig. 5 Principle Compressive and Tensile Stress of Concrete

\section{Stress of Steel Plate of Arch Rib}

Arch rib has a dumbbell-shape section which includes concrete and steel plate wrapped around the concrete. As a part of the steel plate is buried into the large amount of concrete, we can see a quite different variance at the connection section. Stress of steel plate is displayed in the form of Von Mises stress and it is obvious that the average stress of the inserted part of the steel plate is much lower than parts outside. However, the maximum stress $104.7 \mathrm{MPa}$ is much lower than the limited value $210 \mathrm{MPa}$, meaning that the steel plate is safe enough.
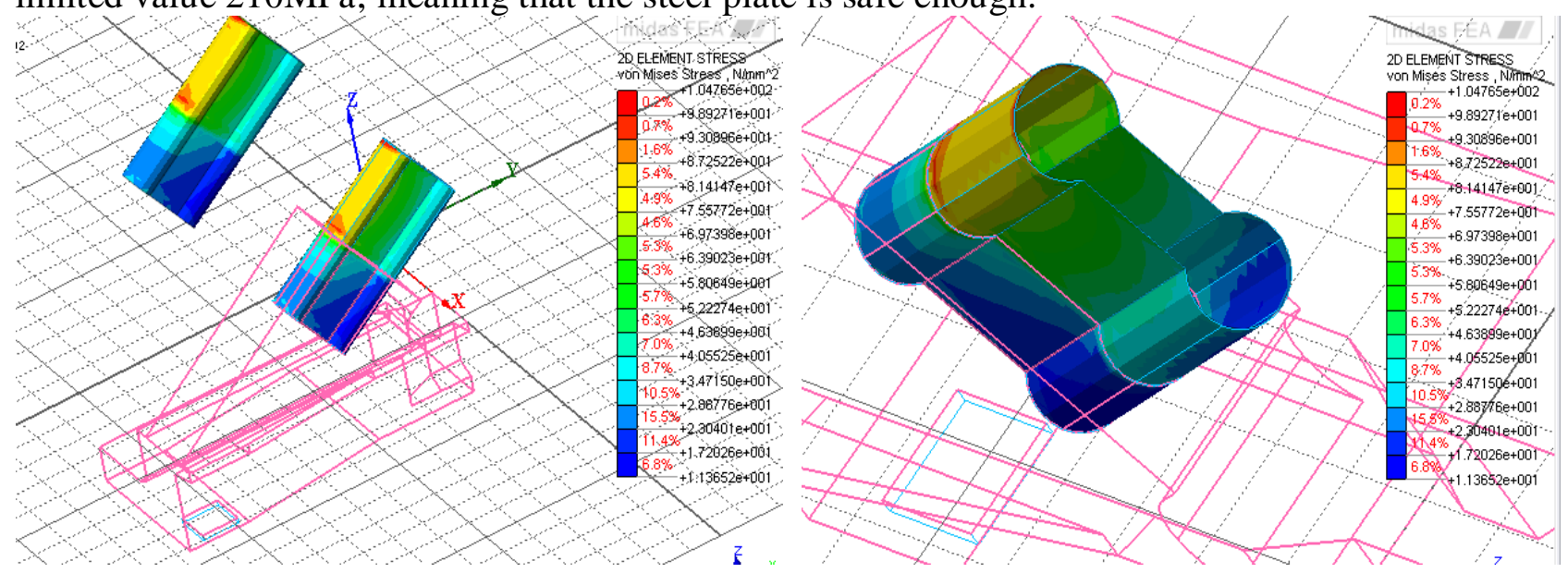

Fig. 6 Von Mises Stress of Steel Plate

\section{Effective Distribution of Stress of Lateral Tendons}

Prestress losses vary along the whole length of the lateral tendons with most serious losses lie in the part near the anchorage point. On the whole, the effective stress remain at 1035MPa.Given the fact that lateral tendons are stretched at $1302 \mathrm{MPa}$, the loss of prestress is around $20 \%$, which is normal. 


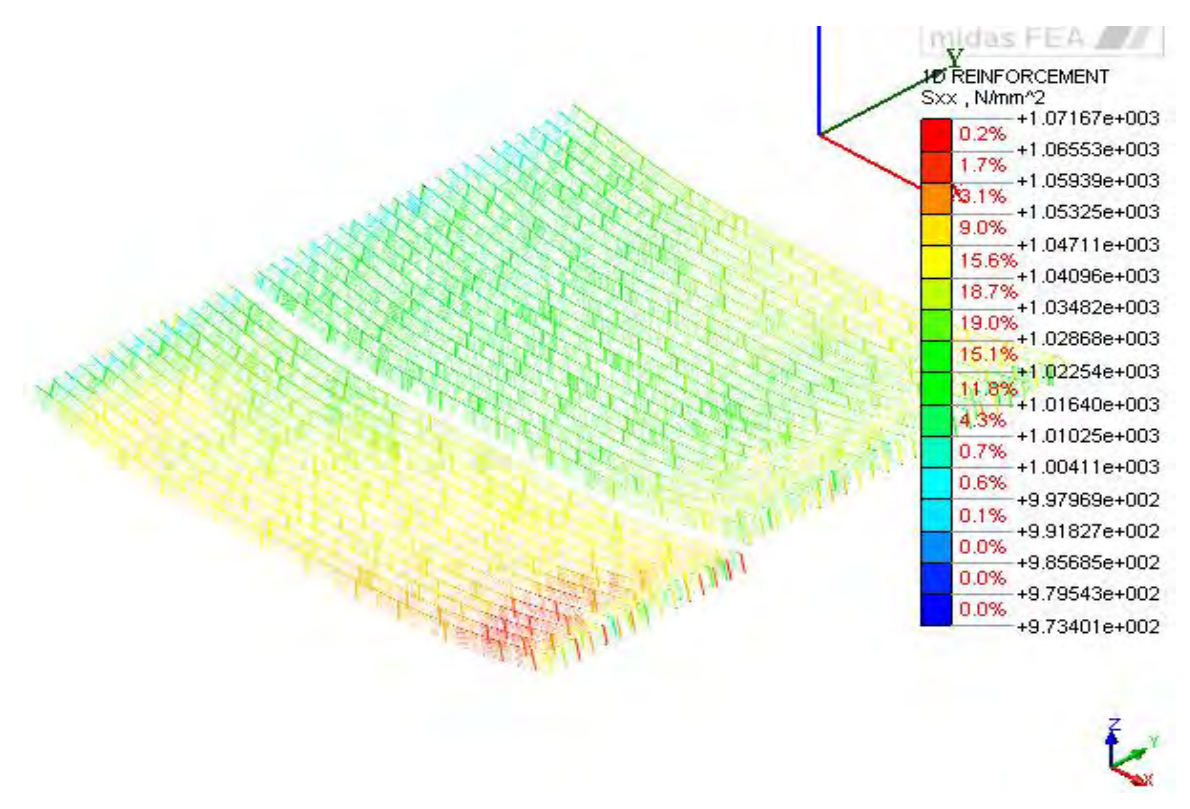

Fig. 7 Effective Stress of Lateral Tendons

\section{Conclusion}

(1)Upper steel plate of the arch rib is subjected to higher stress than the underpart, resulting the concrete inside in danger of destruction, as we can see in Fig.4.Measures such as putting some reinforced steel plate inside the rib are suggested to solve the problem.

(2)Large amount of concrete that connects the rib and the deck beam suffers from significant stress, which can be subdued by placing some reinforcement cage beforehand. It is also noticed that vertical stress cannot be ignored either, which means that three-direction prestressed system can be adopted.

(3)Some parts where the sections change abruptly also need attention because stress concentration can lead to the cracking of concrete. Circular arch connection is constructed to alleviate the stress concentration between the rib and the deck beam. It is also recommended that steel bar should also be placed to reinforce the rigidity.

(4)Supports and anchorage parts are also prone to cracking, which means that the support steel plate need be larger and stronger. Steel bar network and helical reinforcement should also be intensive enough to avoid possible stress concentration.

\section{References}

[1]Xun Wu, Dong Gu. Local Stress Analysis of Arch Foot for Trough Girder and Arch Composite Bridge [C], Progress in Industrial and Civil Engineering III, Part2, P.961-964 (2014).

[2]Xun Wu, Dong Gu. Mechanical Behavior Analysis of Trough Girder and Arch Composite Bridge [C]7th International Conference on Intelligent Computation Technology and Automation. P.957-959(2014).

[3]Gu Xianglin. Theory of Concrete Structure [M], Tongji University Press, Shanghai, P.120-138(2010).

[4]Wang Xucheng. Finite Element Method [M], Tsinghua University, Beijing, P.259-273(2003). 